Background Traffic-related injuries are the largest cause of premature morbidity and leading cause of death among the youth in the UAE. Those injuries are relatively neglected. Our aim was to study epidemiology, risk factors and outcome of hospitalised injured patients 15-24 years in order to give recommendations for prevention.

Methods We prospectively studied all youth patients with trafficrelated injuries admitted to $\mathrm{Al}$ Ain or Tawam Hospitals, Al-Ain City, or who died after arrival to the hospital, during an 18 months period. Demography, location and time of injury, other body region, severity, hospital and intensive care unit (ICU) stay were analysed.

Results 333 patients having a mean age of 20 years (SD 2.5) were studied. $87.1 \%$ were males and $71.5 \%$ were UAE nationals. The most common location for injury was highway and street $(82.8 \%)$ followed by off-road (7.2\%). Majority of injured patients $(69.6 \%)$ were drivers or front-seat passengers, followed by back seat passengers (15.6\%), motorcyclists $(8.7 \%)$ and pedestrians (4.5\%). Rollover was most often crash mechanism (29.7\%), followed by front crash $(29.4 \%)$ and side-angle (16.2\%). 15\% of patients were ejected from the car during rollover crash. Evening (18-24) was the most common time of the day $(33.5 \%)$ and Sunday the most common day of the week (20.1\%) when crash occured. $19.8 \%$ of the patients were admitted to the ICU. Median Glasgow Coma Scale was 15 (Range 315), Injury Severity Score 5 (1-41), Revised Trauma Score 12 (712) and median total hospital stay was 3 (Range 1-73). 9 (2.7\%) patients died.

Conclusions Young UAE-national males are at a higher risk of being injured at traffic. Rollover crash was frequent with high risk of ejection. Promotion of traffic safety and enforcement of safety legislation is neccesary.

\section{PREVENTING MOTOR VEHICLE-RELATED FATALITIES: A COLLABORATIVE PROJECT TO ENHANCE CORONIAL DATA CAPTURE AND USE}

${ }^{1,2,3}$ Sarah A Richmond, ${ }^{1}$ Devon Williams, ${ }^{4}$ Ian Pike, ${ }^{5}$ Dirk Huyer, ${ }^{6}$ Lisa Lapointe, ${ }^{1,7}$ Colin Macarthur, ${ }^{1,7}$ Andrew Howard. ${ }^{1}$ Hospital for Sick Children, Canada; ${ }^{2}$ York University, Canada; ${ }^{3}$ University of Calgar, Canada; ${ }^{4}$ University of British Columbia, Canada; ${ }^{5}$ Ministry of Community Safety and Correctional Services, Ontario Canada; ${ }^{6}$ Ministry of Justice, British Columbia, Canada; ${ }^{7}$ University of Toronto, Canada

\subsection{6/injuryprev-2016-042156.524}

Background Child fatalities due to motor vehicle collisions (MVCs) are a significant burden in Canada. Data specific to these deaths are often referenced, yet few Canadian jurisdictions systematically collect comprehensive details of all child occupant and pedestrian MV fatalities reducing the effectiveness of informing and setting targets for injury prevention initiatives.

Methods This project had two objectives; 1): To document the details of injuries and specific crash circumstances of all fatally injured child and youth (0-18 years) occupants and pedestrians through review of two provincial coroner case files (2004-2012). 2): To introduce recommendations toward standardised data collection procedures for use by coroners, specific to child and youth occupants and pedestrians involved in fatal MVC to: a) support revision of procedures, processes, and practices to facilitate detailed data capture by coroners; and b) to improve information transfer to inform prevention initiatives.
Results Phase 1: Review of death investigation files $(\mathrm{n}=317)$ did not allow ascertainment of suitable detail about injuries $(56.5 \%, \mathrm{n}=160)$, restraint status $(38.1 \%, \mathrm{n}=121)$ and crash type $(7.3 \%, \mathrm{n}=23)$. Data obtained in the retrospective review revealed $43 \%$ (95\% CI: 36.3, 50.0) of cases were side impact collisions, and $40.0 \%$ (95\% CI: $33.0,48.0)$ of the fatalities were reported improperly or unrestrained. Phase 2: A standardised form was developed and provided to each provincial coroner service to facilitate consistent and detailed data collection. Prospective data collection reduced missing data to $0 \%$.

Conclusions Review of data obtained from review of child and youth fatalities demonstrated a significant proportion of deaths followed side impact collisions without use of restraint systems; however, detailed information about MVC circumstances and injury details were not present in the investigation files. Stakeholder involvement plays a pivotal role in attaining data that are imperative to the development of effective injury prevention products, policies and practices.

\section{YOUNG DRIVER CRASHES - THE INFLUENCE OF ROAD SINUOSITY}

${ }^{1}$ Sarah J Jones, ${ }^{2}$ Ronan A Lyons. ${ }^{1}$ Public Health Wales; ${ }^{2}$ Swansea University

\subsection{6/injuryprev-2016-042156.525}

Background Young drivers (YD) are at high risk of crashing because of their age and inexperience, leading some to 'test' themselves on roads that they perceive to be more challenging. While this may have applied more to male YD in the past, crash data indicate that whilst male YD crashes have decreased rapidly in recent years, female YD crashes have decreased much more slowly. Research suggests that female YD are beginning to show behaviours previously seen as 'male' and linked to crash risk. This paper aimed to examine the links between road crashes amongst male and female YD and older drivers (OD) and road sinuosity.

Methods Police road crash data on single vehicle crashes were analysed for Wales for 2000-2013. Young drivers were aged 1719 years and older drivers aged 30-59 years. Each crash was linked to the road network segment (length of road between two consecutive junctions) on which it occurred. Sinuosity of the segment was the ratio of the actual segment length to the straight line distance between start and end of the segment. Analysis was by year, for males and females and for night-time $\mathrm{v}$ day time.

Results For 17-19 year male YD, 95 ${ }^{\text {th }}$ percentile sinuosity values ranged from 1.14 to 1.24 , with no trends. For females aged 17$19,95^{\text {th }}$ percentile values ranged from 1.12 to 1.36 and showed a trend to increasing sinuosity of road crash segments. Amongst OD $95^{\text {th }}$ percentile sinuosity values were lower (1.11-1.28 for males, 1.12-1.31 for females) and decreased over time.

Conclusions YD crashes occur on more sinuous roads than OD crashes. This confirms previous findings around road type and relates specifically to the section of road on which the crash occurred. Realistically though, making the road network less sinuous is not a viable intervention; therefore addressing factors that place YD at higher risk on these roads is important. For YD, this means restricting alcohol consumption, passenger carriage and night-time driving, in short Graduated Driver Licensing. 


\section{THE DEVELOPMENT AND EVALUATION OF AN AUSTRALIAN CHILD PEDESTRIAN SAFETY CAMPAIGN}

Clare Murray, Ioni Lewis, Alexia Lennon, Kim Vuong, Narelle Haworth. Queensland University of Technology, CARRS-Q, Australia

\subsection{6/injuryprev-2016-042156.526}

Background Road crossing is a complex activity and children's risk of pedestrian crashes is greater due to their underdeveloped perceptual and cognitive skills.

This project involved the design and evaluation of a child pedestrian safety campaign, guided by an Extended Theory of Planned Behaviour. The evaluated component consisted of a short $(30 \mathrm{sec})$ video that sought to raise parental road safety awareness and deliver the safety message that parents should hold children's hands in carparks and while crossing the road.

Methods 400 parents of children 3-9 years responded to an online survey. Parents were randomly assigned to either Intervention ( $\mathrm{n}=200)$ or Control $(\mathrm{n}=200)$ groups. Both groups received the same attitudinal and demographic questions. Intervention parents also viewed a $30 \mathrm{sec}$ safety message video and received questions about message interpretation, acceptance, and intentions to perform the suggested behaviour (holding hands).

Results Following one-off exposure to the video, though not statistically significant, the Intervention group reported stronger intentions to hold their child's hand when crossing a road $(\mathrm{M}=4.78, \mathrm{SD}=0.55)$, or in a carpark $(\mathrm{M}=4.73, \mathrm{SD}=0.63)$ in the coming month, than parents in the Control group $(\mathrm{M}$ 4.71, $\mathrm{SD}=0.62$ and $\mathrm{M}=4.72, \mathrm{SD}=0.54$ respectively). Also, the Intervention group reported higher levels of Perceived Behavioural Control (roads, $\mathrm{M}=4.63, \mathrm{SD}=0.55$; carparks, $\mathrm{M}=4.65, \mathrm{SD}=0.57$ ) than parents in the Control group (roads, $\mathrm{M}=4.51, \mathrm{SD}=0.61$; carparks, $\mathrm{M}=4.54, \mathrm{SD}=0.60$ ).

Intervention group parents reported the video was appropriate in content $(\mathrm{M}=4.39, \mathrm{SD}=0.74)$ and tone $(\mathrm{M}=4.19$, $\mathrm{SD}=0.80)$, and that they were likely to adopt the strategy presented $(M=4.20, S D=0.96)$, which they reported as effective $(\mathrm{M}=4.04, \mathrm{SD}=0.92)$.

Conclusions Although parental intentions were high in both groups, these findings provide some support for the persuasiveness of the campaign video. Intervention group parents reported consistently higher intentions to hold their children's hands, and believed that this strategy was something that they could enact easily. The implications of these findings on future research and practice for child pedestrian safety are discussed.

\section{A ONE YEAR STUDY OF ROAD TRAFFIC DEATHS AND INJURIES IN QATAR TO GUIDE POLICIES TO REDUCE MORTALITY AND MORBIDITY}

1,2Lawrence Tallon, ${ }^{2}$ Rafael Consunji. ${ }^{1} /$ mperial College London, UK; ${ }^{2}$ Hamad Medical Corporation, Qatar

\subsection{6/injuryprev-2016-042156.527}

Background Even though Road Traffic Injury [RTI] death rates have declined in Qatar, ${ }^{1}$ they remain three times higher than Western European countries and are the leading cause of death. ${ }^{2}$ This study will collect and analyse key sources of RTI data from Hamad Medical Corporation [HMC], the main national healthcare provider, to better define RTI epidemiology and make policy recommendations for national road safety priorities in Qatar.

Methods A retrospective analysis of RTI data from three important sources of health sector data: the HMC Ambulance Service, major Emergency Department [ED] and trauma registry was conducted for a 12-month period in 2013-14. Standard measures of central tendency were computed and comparisons were made by age, gender, nationality and relative risk.

Results 13,000 patient episodes were collected, summarised and analysed: 10,063 ambulance transportations, including 867 trauma patients, and 2,963 other ED visits. The results identify the key demographic, temporal and geographical features of this public health emergency. Indigenous Qatari males aged 15-19 have a relative risk of RTI 8-11 times higher than the general population and those aged 20-24 have a relative risk 6-9 times higher. RTIs in those aged 25 and above are overwhelmingly in non-Qataris and vary substantially in type of road use between the other Arabic and South Asian residents of this heterogeneous population. The results identify temporal, seasonal and cultural effects associated with RTIs and a map of accident "hot spots" by geographical zone.

Conclusions It is possible to identify with a high degree of probability which road users are most at risk of harm, how, when and where. Using predictive data, public policy makers may be able to more effectively target regulatory, technological and behavioural interventions to those most at risk of harm. These interventions should focus on young male drivers, especially indigenous Qatari, and expatriate pedestrians, especially migrant labourers.

\section{REFERENCES}

1 Mamtani R, Al-Thani MH, Al-Thani AA, Sheikh Jl, Lowenfels AB. Motor vehicle injuries in Qatar: time trends in a rapidly developing Middle Eastern nation. Inj Prev 2012 Apr;18(2):130-2. doi: 10.1136/injuryprev-2011-040147. Epub 2011 Oct 12.

2 Consunji RJ, Peralta RR, Al-Thani H, Latifi R. The implications of the relative risk for road mortality on road safety programmes in Qatar. Inj Prev 2015 Apr;21(e1): e105-8. doi: 10.1136/injuryprev-2013-040939. Epub 2014 Jan 28.

\section{WILL GRADUATED DRIVING LICENCING HAVE MIXED RESULTS FOR REDUCING ROAD INJURY? A QUALITATIVE STUDY IN THE UK}

${ }^{1}$ Judith Green, ${ }^{1}$ Rebecca Steinbach, ${ }^{2}$ Nicola Christie. ${ }^{1}$ London School of Hygiene and Tropical Medicine, UK; ${ }^{2}$ University College London, UK

\subsection{6/injuryprev-2016-042156.528}

Background Graduated Driving Licences (GDL) have the potential to reduce injuries in novice drivers, who are at relatively high risk. However, there are concerns that some risk taking behaviour may be exacerbated by restrictions on, for instance, lift giving. Within the UK, a GDL scheme is planned for Northern Ireland (NI), but not other UK countries. We conducted qualitative research with young adults and parents in NI, England and Wales to identify potential impacts of GDL on injury risk to inform a future evaluation.

Methods Group interviews were held with 16 groups of young adults aged 16-21 and 4 groups of parents. A topic guide covered transport mode choices, incentives for learning to drive, experiences of driving/being a passenger, driving outside the system, telematics and potential impact of GDL restrictions.

Results In rural areas, cars remain essential for accessing work and study for young adults, and for providing spaces to socialise. Restricting provision of lifts for peers would erode mutual support that was part of informal economies. Risky driving (overcrowding, speeding, driving without a licence) was widely reported, and unlikely to be affected by new restrictions. Drink driving was universally disapproved of. Views on telematics were divided, with some in favour of the likely reduced insurance 